\title{
Preparing the Personal Physician for Practice: What We've Learned and Where We Need to Go
}

Warren Newton, MD, MPH; Elizabeth Baxley, MD

(Fam Med. 2018;50(7):499-500.)

doi: 10.22454/FamMed.2018.398588

$\mathbf{T}$ he Preparing the Personal Physician for Practice (P4) project has been like a coastal lighthouse, helping us navigate the shoals of transforming residency programs and guiding us to the next harbor. Carney and colleagues' report ${ }^{1}$ in this issue of Family Medicine is a valuable summary of the immense amount of work of the P4 residencies and an outstanding research team.

It is important to reflect on where we are. The major messages of $\mathrm{P} 4$ for our specialty are clear:

a. Family medicine residencies are interested in and capable of significant experimentation in design and conduct of residency training. Eighty-four residencies—about a sixth of all residencies in the country-applied to participate, undeterred by significant data submission requirements and lack of funding.

b. The external evaluation team played a key role, requiring common data collection and surveying all graduates 18 months out. Their engaged approach supported individual residencies in asking and answering important questions in a way that others can learn from.

c. Accreditation Council for Graduate Medical Education (ACGME) residency review is compatible with innovation. When P4 started, a common concern was that our residency review committee was not supportive of innovation. It is now clear that substantial innovation, when thoughtful and proactive, is possible within the ongoing accreditation process. Citations happen - but not significantly more frequently than in programs which have not chosen to change. We are grateful to the Family Medicine Review Committee and its leadership for being clear about this.

d. What residencies have chosen to change is also important. Given the opportunity, they chose a wide variety of areas, from duration of training, to process of care in residencies, to core competencies of teambased care, and many other topics. These are the hot spots for future reform of residency training: salient issues are the duration of training (now the subject of a formal trial supported by the American Board of Family Medicine), and scope of practice.

So where are we now? Since the publication of the Future of Family Medicine report in $2004,{ }^{2}$ half a generation has passed. With respect to residency training, many aspects of the new model of practice (EHRs, team-based care, training in quality improvement) have been incorporated broadly into routine residency training. At the ACGME level, the Next Accreditation System has been implemented, with clinical competence committees and regular review of developmental milestones for residents. For individual residencies, however, it remains unclear how often patients have been engaged in changing the process of their care, how much measured access or quality outcomes have improved, or how widespread teaching of new competencies in team-based care has been.

From the Department of Family Medicine, University of North Carolina School of Medicine, Chapel Hill, NC (Dr Newton), and the American Board of Family Medicine, Lexington, KY (Drs Newton and Baxley). 
Where should family medicine residency training go in the future? Here, the lessons from $\mathrm{P} 4$ should be considered alongside those of the I3 collaboratives and the Colorado Family Medicine Residency Patient-Centered Medical Home (PCMH) project, which are also large-scale residency collaboratives with over 20 published reports. The I3 Collaborative has emphasized that "the practice is the curriculum," with iterations since 2005 focusing successively on improving residency chronic care, ${ }^{3}$ obtaining PCMH recognition, ${ }^{4}$ improving population health, ${ }^{5}$ and currently implementing the quadruple aim, whereas the Colorado family medicine residencies focused on clinical adoption of the PCMH and associated curriculum. ${ }^{6,7}$

We believe that the job of innovation in family medicine residency education is not complete. A first principle should be to focus on the clinical outcomes of care our residencies provide - the triple aim, understood as measured quality of care, patient experience, and cost of care-while attending to the experience of our residency clinical teams. There is increasing evidence that the clinical imprinting in residency has long-term effects on quality and cost, ${ }^{8-10}$ and that family medicine residencies vary greatly in outcomes across each of the dimensions of the triple aim, ${ }^{11}$ unexplained by payer, age, or race. If we want our graduates to help address the triple aim, we need to address more directly the care they provide in residencies.

A second principle is to address sustainability. We know from studies of practice transformation that innovation, though very difficult, is only part of the task. The bigger challenge is sustaining clinical systems change, especially when there is little change in payment, and often chaotic change in the environment of care. So too with residency redesign. P4 begs the question: do innovations endure, and what helps them do so?

A third principle is the importance of moving beyond single residencies to design, evaluate, and disseminate changes in residency education, not only for statistical power but also to serve as learning networks. Change is difficult; sharing best practices and learning from failures provides tremendous support. Developing interventions in residency education will require both funding and consensus across residencies about what should be done. Both are challenges.

We should keep in mind the most important levers the discipline has to promote change in residencies - the upcoming revisions of the family medicine residency guidelines document and the milestones. As emphasized by the then-Institute of Medicine Global Forum on Innovation in Health Professional Education, regulators are increasingly looking to create positive change in the programs they accredit. ${ }^{12}$ In addition, over the last several years, the American Board of Family Medicine has worked with the Association of Family Medicine Residency Directors to develop a survey of graduates 3 years out. Given the very good response rate of graduates, residencies now have valid benchmark data on a wide variety of outcomes.

Our future is in our hands.

CORRESPONDING AUTHOR: Address correspondence to Dr Warren Newton, University of North Carolina at Chapel Hill-Family Medicine, CB\#7595 William Aycock Bldg, Chapel Hill, NC 27599. 919-966-5600. warren_newton@med.unc.edu.

\section{References}

1. Carney PA, Eiff MP, Waller E, Jones SM, Green LA. Redesigning residency training: summary findings from the preparing personal physician for practice (P4) project. Fam Med. 2018;50(7):503-17.

2. Green LA, Graham R, Kilo C, Spann SJ, Bodgwic SP, Swanson J. Task force 1. Report of the task force on patient expectations, core values, reintegration, and the new model of family medicine. Ann Fam Med. 2004;1(suppl 1):S33-S50.

3. Newton W, Baxley E, Reid A, Stanek M, Robinson M, Weir S. Improving chronic illness care in teaching practices: learnings from the $\mathrm{I}^{3}$ collaborative. Fam Med. 2011;43(7):495-502.

4. Reid A, Baxley E, Stanek M, Newton W. Practice transformation in teaching settings: lessons from the $\mathrm{I}^{3} \mathrm{PCMH}$ collaborative. Fam Med. 2011;43(7):487-494.

5. Donahue KE, Reid A, Lefebvre A, Stanek M, Newton WP. Tackling the triple aim in primary care residencies: the I3 POP Collaborative. Fam Med. 2015;47(2):91-97.

6. Jortberg BT, Fernald DH, Dickinson LM, et al. Curriculum redesign for teaching the PCMH in Colorado Family Medicine Residency programs. Fam Med. 2014;46(1):11-18.

7. Buscaj E, Hall T, Montgomery L, et al. Practice Facilitation for PCMH Implementation in Residency Practices. Fam Med. 2016;48(10):795-800.

8. Asch DA, Nicholson S, Srinivas S, Herrin J, Epstein AJ. Evaluating obstetrical residency programs using patient outcomes. JAMA. 2009;302(12):1277-1283.

9. Sirovich BE, Lipner RS, Johnston M, Holmboe ES. The association between residency training and internists' ability to practice conservatively. JAMA Intern Med. 2014;174(10):1640-1648

10. Chen C, Petterson S, Phillips R, Bazemore A, Mullan F. Spending patterns in region of residency training and subsequent expenditures for care provided by practicing physicians for Medicare beneficiaries. JAMA. 2014;312(22):2385 2393.

11. Paige C, Reid A, Drostin A, Newton W. Variation in residency triple aim measures: implications of family medicine residencies' clinical signatures. J Grad Med Educ. In press.

12. National Academies of Sciences, Engineering, and Medicine. 2017. Exploring the role of accreditation in enhancing quality and innovation in health professions education: Proceedings of a workshop. Washington, DC: The National Academies Press. 